\title{
Fundus autofluorescence in blunt ocular trauma
}

\author{
Autofluorescência do fundo de olho no trauma ocular contuso
}

Ricardo luz leitão Guerra ${ }^{1}$, Igor Sandes Pessoa da Silva ${ }^{2}$, Eduardo Ferrari Marback ${ }^{3}$, Otacílio de Oliveira Maia Jr. ${ }^{2}$, Roberto Lorens Marback ${ }^{3}$

\begin{abstract}
Purpose: To describe the findings of fundus autofluorescence (FAF) imaging in patients with blunt ocular trauma.

Methods: In this non-interventional retrospective study, we reviewed medical records and imaging examination results. The data analyzed included gender, age, laterality, trauma etiology, time between trauma and imaging, visual acuity, changes in the retinal periphery, fundus examination results, and FAF imaging findings. FAF imaging was performed using a Topcon TRC-50DX Retinal Camera (Tokyo, Japan). Results: Eight eyes from 8 patients were studied. The mean age was 27.6 years (range, 19-43 years). Men ( $n=7$ ) were more frequently affected by blunt ocular trauma than women $(n=1)$. Physical aggression was the most common trauma etiology $(n=3)$, followed by accidents with fireworks $(n=2)$. Other causes were car accidents $(n=1)$, occupational trauma caused by a grinder $(n=1)$, or being hit by a stone $(n=1)$.Visual acuity ranged from 20/80 to light perception. Traumatic pigment epitheliopathy (TPE) was identified in 5 cases, choroidal rupture in 3 cases, subretinal hemorrhage in 3 cases, and Purtscher's retinopathy in 1 case. Hypoautofluorescence was observed in cases of choroidal rupture, recent subretinal hemorrhage, and intraretinal hemorrhage, and in two cases of TPE. Hyperautofluorescence was observed in cases of old subretinal hemorrhage and at the edge of the lesion in two cases of choroidal rupture. Mild hyperautofluorescence was observed in the posterior pole in Purtscher's retinopathy. Three cases of TPE exhibited hypoautofluorescence with diffuse hyperautofluorescent areas.

Conclusion: FAF imaging is a non-invasive method for assessing changes in the posterior segment of the eye resulting from blunt ocular trauma. Furthermore, this technique provides valuable information. We described the findings of FAF imaging in cases of TPE, choroidal rupture, subretinal hemorrhage, and Purtscher's retinopathy.
\end{abstract}

Keywords: Trauma; Retinal pigment epithelium; Retinal diseases; Ocular trauma

\section{RESUMO}

Objetivo: Descrever os achados do exame de autofluorescência do fundo de olho (AFF) em pacientes vítimas de trauma ocular contuso.

Métodos: Estudo retrospectivo, não intervencionista, realizado através da revisão de prontuários e exames de imagem. Os dados analisados foram: sexo, idade, lateralidade, etiologia do trauma, tempo decorrente entre o trauma e a realização do exame, acuidade visual, alterações na periferia da retina, diagnóstico fundoscópico e achados ao exame de AFF (realizada no aparelho Topcon TRC-50DX Retinal Camera).

Resultados: Oito olhos de 8 pacientes foram estudados. A idade média foi de 27,6 anos (de 19 a 43 anos), o sexo masculino ( $n=7$ ) foi mais acometido do que o feminino ( $n=1)$, agressão física foi a etiologia mais comum do trauma ( $n=3)$, seguido de acidente com fogos de artifício $(n=2)$. Outras causas foram acidente automobilístico $(n=1)$, trauma ocupacional com lixadeira $(n=1)$ e pedrada $(n=1)$. A acuidade visual variou de 20/80 a percepção luminosa. Epiteliopatia pigmentar traumática (EPT) foi identificada em 5 casos, rotura de coroide em 3, hemorragia sub-retiniana em 3 e retinopatia de Purtscher em 1 caso. Hipoautofluorescência foi observada nos casos de rotura de coroide, hemorragia sub-retiniana recente, hemorragia intrarretiniana e em 2 casos de EPT. Hiperautofluorescência foi visualizada nos casos de hemorragia sub-retiniana em degradação, na borda de 2 casos de roturas de coroide e discretamente no polo posterior na retinopatia de Purtcher. Três casos de EPT apresentaram hipoautofluorescência com pontos hiperautofluorescentes difusos.

Conclusão: O exame de AFF permite avaliar as alterações do segmento posterior do olho decorrentes do trauma ocular contuso de forma não invasiva, somando informações valiosas. Foram descritos achados do exame em casos de epiteliopatia pigmentar traumática, rotura de coroide, hemorragia sub-retiniana e retinopatia de Purtscher.

Descritores: Trauma; Epitélio pigmentado da retina; Doenças retinianas; Traumatismos oculares

\section{INTRODUCTION}

Blunt ocular trauma is an injury that does not compromise the integrity of the eye wall(1). It manifests in various ways in the posterior segment of the eye and causes serious sequelae ${ }^{(1)}$. Vitreous hemorrhage, retinal edema (commotio retinae), choroidal rupture, macular holes, retinitis sclopetaria, retinal rupture, and retinal dialysis are complications involving the posterior segment in blunt ocular trauma(1).

Fundus autofluorescence (FAF) imaging is a method that uses a non-invasive imaging technique to evaluate the integrity of the retinal pigment epithelium (RPE) (2). A homogeneous pattern on FAF images indicates normal metabolic activity of the PER cells, whereas decreased fluorescence (hypoautofluorescence) suggests impairment of photoreceptors or PER cells $s^{(3)}$.
The usefulness of FAF imaging is well described in several eye conditions such as retinal dystrophies(2) and pigmented intraocular tumors ${ }^{(4)}$. This study aimed to describe the findings of FAF imaging in patients with blunt ocular trauma. In the reviewed literature, we only found three articles describing the findings of FAF imaging in patients that showed changes in the posterior segment associated with blunt ocular trauma ${ }^{(5-7)}$.

\section{METHODS}

This was a non-interventional retrospective study. In this study, the medical records and imaging results of patients, who were diagnosed with injury caused by blunt ocular trauma involving the posterior segment, were reviewed.
Submitted for publication: December 19,2013

Accepted for publication: April 2, 2014

Study conducted at Retina and Vitreous Service, Hospital São Rafael, Fundação Monte Tabor, Salvador, BA, Brazil.

${ }^{1}$ Clínica de Olhos Leitão Guerra, Salvador, BA, Brazil.

2 Hospital São Rafael, Fundação Monte Tabor, Salvador, BA, Brazil.

${ }^{3}$ Faculdade de Medicina da Bahia, Universidade Federal da Bahia, Salvador, BA, Brazil.
Funding: No specific financial support was available for this study.

Disclosure of potential conflicts of interest: None of the authors have any potential conflicts of interest to disclose.

Corresponding author: Ricardo Leitão Guerra. Rua Catarina Paraguaçu, 8 - Salvador (BA) 40150-200 - Brazil - E-mail: ricardo@leitaoguerra.com.br 
All patients were submitted to an ophthalmologic examination, color fundus photography, and FAF at Hospital São Rafael-Fundação Monte-Tabor in Salvador, Bahia-Brazil from 02/01/2011 to 01/31/2013. Patient selection was based on a diagnosis of ocular blunt trauma collected from the institution's fundus photography registry book. Patients with incomplete data were excluded from the study. This study was approved by the research ethics committee of the same institution (CAAE - 14929313.4.0000.0048).

The data analyzed included sex, age, laterality, trauma etiology, time between trauma and imaging, visual acuity, changes in the retinal periphery, fundus examination results, and FAF imaging findings. FAF imaging was performed using a Topcon TRC-50DX Retinal Camera (Tokyo, Japan)

\section{RESULTS}

Eight eyes in 8 patients were studied. No patient was excluded from the study. A summary of the cases is shown in table 1; color fundus photography and FAF findings are shown in figures 1 and 2. The mean age was 27.6 years (range, 19-43 years), and men $(n=7)$ were more frequently affected by blunt ocular trauma than women $(n=1)$, and the right eye $(n=5)$ was more affected than the left eye $(n=3)$.

Physical aggression was the most common trauma etiology $(n=3)$, followed by accidents with fireworks $(n=2)$. Other causes were car accidents $(n=1)$, occupational trauma caused by a grinder $(n=1)$, and being hit by a stone $(n=1)$.

Visual acuity ranged from 20/80 to light perception, and 2 patients exhibited changes on peripheral retinal examination that included retinal dialysis with peripheral retinal detachment $(n=1)$ and rupture of the retina without retinal detachment $(n=1)$.

Traumatic pigment epitheliopathy (TPE) was the most common finding $(n=5)$, followed by choroidal rupture $(n=3)$, subretinal hemorrhage $(n=3)$, and Purtscher's retinopathy $(n=1)$. Hypoautofluorescence was observed in cases of choroidal rupture, recent subretinal hemorrhage, intraretinal hemorrhage, and in 2 cases of TPE. Hyperautofluorescence was observed in cases of old subretinal hemorrhage and at the edge of the lesion in 2 cases of choroidal rupture. Mild hyperautofluorescence was observed in the posterior pole in Purtscher's retinopathy. Three cases of TPE exhibited hypoautofluorescence with diffuse hyperautofluorescent areas. These findings are summarized in table 2.

\section{DISCUSSION}

\section{TPE}

TPE usually occurs in cases of severe trauma following resolution of commotio retinae ${ }^{(5,8)}$. When the macular region is involved, TPE is associated with poor visual prognosis ${ }^{(5,8)}$. In these cases, FAF imaging shows a hypoautofluorescent area alternating with punctiform hyperautofluorescent lesions ${ }^{(5,6)}$.
In this series of cases, 5 of the 8 patients had TPE (cases 4, 5, 6, 7 , and 8). Three patients (cases 6, 7, and 8) exhibited the characteristic pattern on FAF images, which is described above. In the other 2 cases (cases 4 and 5), FAF imaging showed a hypoautofluorescent lesion corresponding to the affected region. We observed that FAF imaging was more effective than color fundus photography for the identification and definition of the areas affected by TPE.

\section{Choroidal rupture}

Choroidal rupture can be observed on FAF images as a hypoautofluorescent line, and in some cases, FAF imaging provides better visualization and definition of the lesion than color fundus photography ${ }^{(5,7)}$. In some cases, there is a hyperautofluorescent ring surrounding the lesion, which may correspond to hyperplasia of RPE that occurs as the rupture heals ${ }^{(5)}$.

In the 3 patients with choroidal rupture (cases 2, 3, and 4), FAF imaging showed a hypoautofluorescent lesion corresponding to the site of rupture. In 2 cases (cases 3 and 4), a hyperautofluorescent ring was observed at the edge of the lesion. The time elapsed between the trauma and examination was longer for these patients, which confirms the hypothesis of hyperautofluorescence at the edge of the lesion is related to the healing process of a choroidal rupture.

\section{SUBRETINAL HEMORRHAGE}

Recent subretinal hemorrhage (when there is no degradation of blood cells) presents itself as a hypoautofluorescent lesion on FAF images $^{(5)}$. As erythrocytes are degraded and the blood turns yellowish, the appearance on FAF images becomes hyperautofluorescent ${ }^{(5)}$. We note that, in this situation, devitalized blood cells are harmful to photoreceptors and are associated with a poorer visual prognosis ${ }^{(5,9)}$.

Three cases described in this study exhibited signs of subretinal hemorrhage; 1 case of recent hemorrhage (case 2 ) and 2 cases of old hemorrhage (cases 3 and 4). The results of the FAF imaging examinations in these patients agreed with those described in the literature, and they allowed us to better define the extension of a subretinal hemorrhage, both in recent cases and in cases wherein blood cell degradation was observed. The authors believe that this characteristic makes FAF imaging a useful tool for identifying and monitoring patients who have subretinal hemorrhage for which there is no indication of surgical treatment.

\section{Purtscher's Retinopathy}

One patient (case 1) was diagnosed with Purtscher's retinopathy, and FAF imaging was performed during the acute phase. We did not find in the literature a description of FAF imaging for similar cases (following trauma). We searched for the terms "Purtscher", "Retinopathy", and "Autofluorescence" in MEDLINE and SCIELO databases.

Only 1 report of a Purtscher-like retinopathy case (following pancreatitis) was found in the literature, which described the results of

Table 1. Summary of cases studied

\begin{tabular}{|c|c|c|c|c|c|c|c|c|}
\hline & Gender & Age & Eye & Trauma etiology & Time & VA & Periphery & Diagnosis \\
\hline Case 1 & M & 27 & LE & Car accident & 6 days & $20 / 200$ & Normal & Purtscher \\
\hline Case 2 & M & 25 & LE & Grinder & 5 days & $20 / 200$ & Dialysis & $C R$ \\
\hline Case 3 & $\mathrm{~F}$ & 19 & RE & Physical aggression & 3 months & $20 / 80$ & Normal & $C R$ \\
\hline Case 4 & M & 43 & RE & Fireworks & 8 months & $20 / 200$ & Normal & $\mathrm{CR}+\mathrm{MH}+\mathrm{TPE}$ \\
\hline Case 5 & M & 19 & LE & Stone & 3 months & $C F$ & Normal & EPT \\
\hline Case 6 & M & 16 & RE & Fireworks & 1 month & CF & Normal & $C R+T P E$ \\
\hline Case 7 & M & 32 & RE & Physical aggression & 1 month & CF & Normal & $C R+T P E$ \\
\hline Case 8 & M & 40 & $\mathrm{RE}$ & Physical aggression & 2 months & $L P$ & Rupture & TPE \\
\hline
\end{tabular}

$\mathrm{M}=$ male; $\mathrm{F}=$ female; $\mathrm{RE}=$ right eye; $\mathrm{LE}=$ left eye; $\mathrm{VA}=$ visual acuity; $\mathrm{CF}=$ counting fingers; $\mathrm{LP}=$ light perception; $\mathrm{CR}=$ choroidal rupture; $\mathrm{MH}=$ macular hole; $T P E=$ traumatic epitheliopathy. 

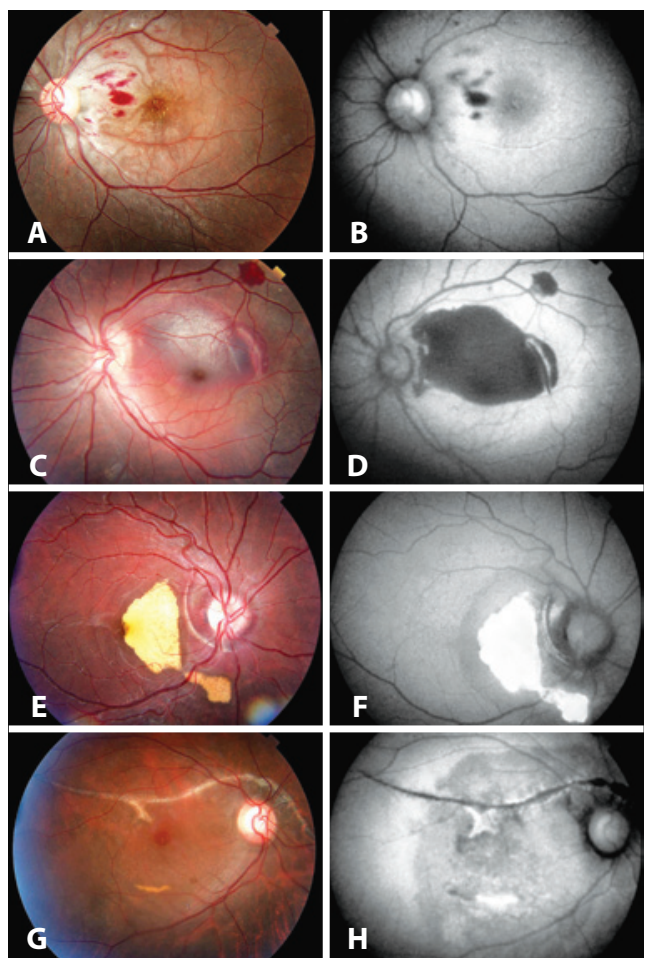

Figure 1.A) Purtscher's retinopathy. B) FAF exhibits hypoautofluorescence in the areas corresponding to intraretinal hemorrhage and mild perimacularhyperautofluorescence.C) Recent subretinal hemorrhage in the macular region, secondary to choroidal rupture temporal to the macula. D) FAF exhibits an extensive hypoautofluorescent area in the region affected by the hemorrhage and a hypoautofluorescent line corresponding to choroidal rupture. E) Choroidal rupture with subretinal hemorrhage showing degradation of subretinal blood. F) FAF exhibits hyperautofluorescence corresponding to the degraded blood. Choroidal rupture as a hypoautofluorescent line associated with the hyperautofluorescent areas. G) Choroidal rupture, degraded subretinal blood, and macular hole 8 months after blunt trauma. H) FAF exhibits a hypoautofluorescent line corresponding to choroidal rupture, a hyperautofluorescent line caused by degraded blood, and moderate hypoautofluorescence in the posterior pole and in the peripapillary region corresponding to the involvement of RPE.

FAF examination ${ }^{(10)}$. In this report, we describe hypoautofluorescence in the areas corresponding to Purtscher's spots, hyperautofluorescence in veins affected by ischemia during the acute phase of retinopathy, and a granular pattern of hyperautofluorescence and hypoautofluorescence in the region previously affected by the Purtscher's spots after the retinopathy had been resolved ${ }^{(10)}$

Contrary to this finding, FAF imaging of the patient described in the present study showed hypoautofluorescence in the areas corresponding to intraretinal hemorrhage and mild hyperautofluorescence surrounding the macular region, corresponding to the sites where Purtscher's spots were observed.

Despite the similar clinical presentation, the difference between the pathophysiological mechanism of Purtscher's retinopathy and that of Purtscher-like retinopathy may explain the disparate results among examinations. The lack of experimental studies or other data in the literature precludes a definitive conclusion.

Moreover, we propose that in the case of the patient who sustained trauma, a different change associated with Purtscher's retinopathy, such as commotio retinae, contributed to hyperautofluorescence in the posterior pole. This hypothesis is consistent with the results described by Lavinsky et al ${ }^{(5)}$. Three cases of commotio retinae exhibited
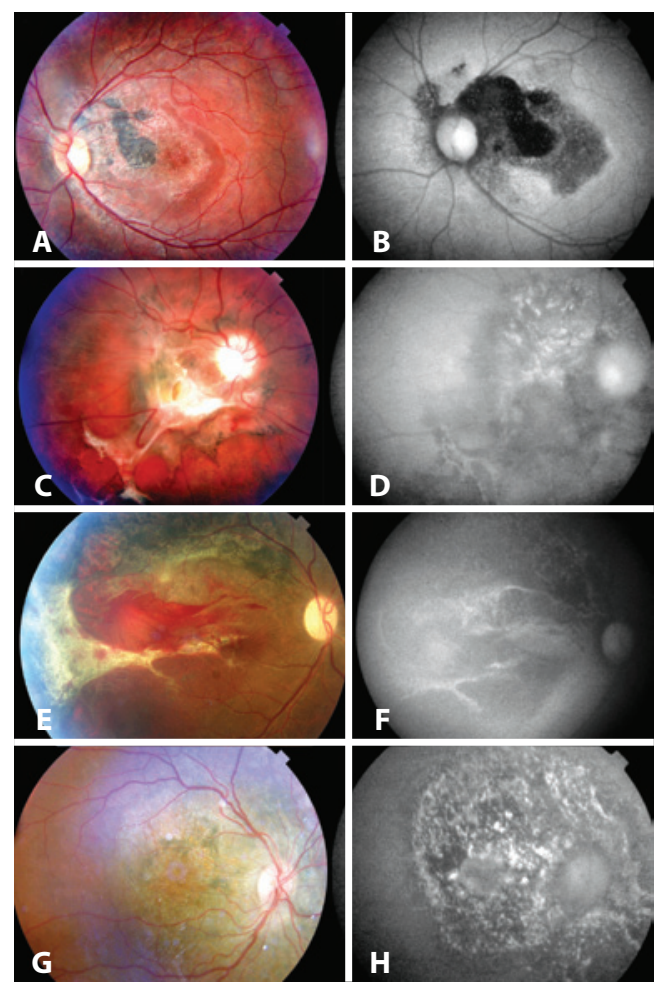

Figure 2. A) Hyperchromic lesion in the papillomacular bundle surrounded by hyperchromic and hypochromic pigment changes in the macular region. B) FAF exhibits a large hypoautofluorescent area affecting the macula. C) Choroidal rupture with extensive subretinal fibrosis, mobilization of the pigment in the posterior pole, and retinal architecture anomalies. D) FAF exhibits a hypoautofluorescent lesion with diffuse hyperautofluorescent areas affecting the posterior pole. E) Subretinal hemorrhage near the area of subretinal fibrosis affecting the temporal macular region. Toward the upper arcade, there is a change in RPR pigmentation. F) FAF exhibits a hypoautofluorescent area with diffuse hyperautofluorescent areas in the affected region, with a prevalence of hypoautofluorescent lesions. G) Slightly decreased RPE pigmentation in the peripapillary region. H) FAF exhibits a hypoautofluorescent lesion with diffuse hyperautofluorescent areas. In this case, FAF resulted in improved delimitation of the lesion compared with color fundus photography.

Table 2. Correlation between the findings of fundus examination and FAF imaging

\begin{tabular}{|c|c|c|c|}
\hline $\begin{array}{l}\text { Fundus } \\
\text { examination }\end{array}$ & $\mathbf{n}$ & FAF imaging & $\mathbf{n}$ \\
\hline \multirow[t]{2}{*}{ Choroidal rupture } & 3 & Hypoautofluorescence at the site of rupture & 3 \\
\hline & & Hyperfluorescence at the edge of the lesion & 2 \\
\hline \multirow[t]{2}{*}{$\begin{array}{l}\text { Traumatic pigment } \\
\text { epitheliopathy }\end{array}$} & 5 & $\begin{array}{l}\text { Alternating hypoautofluorescence and } \\
\text { hyperautofluorescence }\end{array}$ & 3 \\
\hline & & Hypoautofluorescence & 2 \\
\hline $\begin{array}{l}\text { Recent subretinal } \\
\text { hemorrhage }\end{array}$ & 1 & Hypoautofluorescence & 1 \\
\hline $\begin{array}{l}\text { Old subretinal } \\
\text { hemorrhage }\end{array}$ & 2 & Hyperautofluorescence & 2 \\
\hline $\begin{array}{l}\text { Purtscher's } \\
\text { retinopathy }\end{array}$ & 1 & $\begin{array}{l}\text { Perimacular hyperautofluorescence and } \\
\text { hypoautofluorescence corresponding to } \\
\text { hemorrhage }\end{array}$ & 1 \\
\hline
\end{tabular}

$n=$ number of eyes that exhibited the finding.

mild hyperautofluorescence during the acute phases of the disease, which progressed to TPE in a few weeks ${ }^{(5)}$. In the present study, we 
were not able to follow this case because the patient did not return for subsequent visits.

\section{Clinical application}

After analyzing the results of this study and comparing them with the reviewed literature, we believe that FAF imaging plays an important role evaluation of patients who sustain blunt ocular trauma. The main advantages of FAF, according to the literature ${ }^{(5,7)}$, are better lesion definition than color and red free fundus photography that improves the quality of patient follow-up. Longitudinal studies are necessary to establish further advantages of FAF imaging in cases of blunt ocular trauma.

\section{CONCLUSION}

FAF examination is a non-invasive method for assessing changes in the posterior segment of the eye that result from blunt ocular trauma. It provides valuable information. We described the findings of FAF imaging in cases of TPE, choroidal rupture, subretinal hemorrhage, and Purtscher's retinopathy.

\section{REFERÊNCIAS}

1. Posterior segment manifestations of trauma. In: Basic and Clinical Science Course Section 12: Retina and vitreous. American Academy of Ophthalmology. 2011. p.315-33.

2. Coco M, Baba NT, Sallum JM. Avaliação da autofluorescência do fundo de olho nas distrofias de retina com o aparelho Heidelberg Retina Angiograph2. Arq Bras Oftalmol. 2007;70(5):739-45.

3. Ishida T, Ohno-Matsui K, Kaneko Y, Tobita H, Hayashi K, Shimada N, Mochizuki M. Autofluorescence of metastatic choroidal tumor. Int Ophthalmol. 2009;29(4):309-13.

4. Materin MA, Raducu R, Bianciotto C, Shields CL. Fundus autofluorescence and optical coherence tomography findings in choroidal melanocytic lesions. Middle East Afr $J$ Ophthalmol. 2010;17(3):201-6.

5. Lavinsky D, Martins EN, Cardillo JA, Farah ME. Fundus autofluorescence in patients with blunt ocular trauma. Acta Ophthalmol. 2011;89(1):89-94.

6. Mustafa MS, McBain VA, Scott CM. Autofluorescence imaging - a useful adjunct in imaging macular trauma. Clin Ophthalmol. 2010;4:1497-8.

7. Kolomeyer AM, Szirth BC, Nayak NV, Khouri AS. Complimentary imaging technologies in blunt ocular trauma. Oman J Ophthalmol. 2013:6(2):108-11.

8. Sawa M, Ober MD, Spaide RF. Autofluorescence and retinal pigment epithelial atrophy after subretinal hemorrhage. Retina. 2006;26(1):119-20.

9. Yang CS, Chou TF, Liu JH, Hsu WM. Air bag associated posterior segment ocular trauma. J Chin Med Assoc. 2004;67(8):425-31.

10. Giani A, Deiro AP, Sabella P, Eandi CM. Spectral domain-optical coherence tomography and fundus autofluorescence findings in a case of Purtscher-like retinopathy. Retinal Cases \& Brief reports. 2011;5(2):167-70.

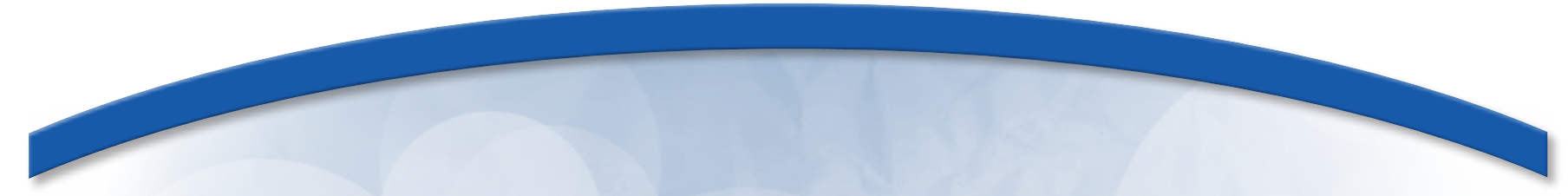

\title{
II Congresso de Estética Periocular da Sociedade Brasileira de Cirurgia Plástica Ocular (SBCPO)
}

\author{
7 e 8 de novembro 2014 \\ Rio Othon Palace \\ Rio de Janeiro - RJ
}

Informações:

Site: www.ciopcongressos.com.br 